\title{
Composition and Heavy Oil Rheology
}

\author{
C. Pierre' ${ }^{1}$ L. Barré ${ }^{1}$, A. Pina ${ }^{1}$ and M. Moan ${ }^{2}$ \\ 1 Institut français du pétrole, let 4, avenue de Bois-Préau, 92852 Rueil-Malmaison Cedex - France \\ 2 Laboratoire de rhéologie, mécanique des structures, université de Bretagne occidentale, \\ 6, avenue Victor-le-Gorgeu, 29285 Brest Cedex - France \\ e-mail: loic.barre@ifp.fr - anabelle.pina@ifp.fr
}

\begin{abstract}
Résumé - Rhéologie des bruts lourds en relation avec leur composition - La forte demande en énergie conduit les industries pétrolières à exploiter les réserves de bruts lourds et extralourds. Ces bruts sont en particulier caractérisés par leur forte viscosité qui rend leur transport en surface impossible sous leur état naturel (pertes de charge importantes). Plusieurs méthodes de traitement existent; afin de les améliorer, il est nécessaire de comprendre l'origine de ces fortes viscosités. Notre démarche a été de réaliser des études rhéologiques et structurales (diffusion de rayons X ou SAXS) afin de relier les propriétés macroscopiques et microscopiques des bruts lourds. Nous avons étudié l'influence des deux composés les plus lourds et les plus polaires des bruts que sont les asphaltènes et les résines. Les résultats ont montré le rôle prépondérant des asphaltènes sur la viscosité des bruts lourds. Deux régimes de viscosité, confirmés en SAXS, ont montré l'existence d'une concentration critique à partir de laquelle les asphaltènes ne sont plus des particules indépendantes et se recouvrent. Le rôle des résines a été développé dans un solvant aromatique puis en ajoutant une molécule modèle des résines : le nonylphénol. Il a été montré que la présence de résines réduit l'influence des asphaltènes sur la viscosité. Leur mode d'action sur les asphaltènes est double : d'une part, elles ont un rôle stabilisant en recouvrant les asphaltènes ; d'autre part, elles ont un effet dissociant en diminuant la taille des asphaltènes et en réduisant leur masse. L'influence des résines a été également confirmée dans le brut réel. Enfin, il a été montré que l'addition modérée d'un alcool dans un solvant aromatique réduisait l'association des asphaltènes.
\end{abstract}

\begin{abstract}
Composition and Heavy Oil Rheology — Increasing energy demand persuades oil companies to exploit heavy crude oil and extra-heavy crude oil resources. These crudes are essentially characterized by high viscosity that makes impossible surface transportation in their natural state (high pressure drops). Our investigation procedure was to perform both rheological and structural experiments (Small Angle X-ray Scattering SAXS) in order to link macroscopic and microscopic properties of crudes. We studied the influence of the two heaviest and most polar components of the crude: asphaltenes and resins. Results showed the major influence of asphaltenes on viscosity of crude oils. Two viscosity domains, confirmed in SAXS, proved the existence of a critical concentration above which asphaltenes are no longer independent particles but are overlapped. Influence of resins has been developed in aromatic solvent and when adding a model molecule of resins: nonylphenol. It has been shown that resins reduce the influence of asphaltenes on viscosity. They act in two ways: in one part, they act as a stabilizing agent by covering asphaltenes and in the other part, they dissociate asphaltenes by diminishing both size and molecular mass of asphaltenes. The influence of resins has been confirmed in real crude. Then it was shown that small addition of alcohol in aromatic solvent reduced the association of asphaltenes.
\end{abstract}




\section{INTRODUCTION}

The increasing oil demand requires the exploitation of heavy and extra-heavy crude oils which reserves are of the same volume as the conventional ones. The exploitation of these reserves is still low, because of their high viscosity, high heavy metals and heteroatoms $(\mathrm{S}, \mathrm{O}, \mathrm{N})$ contents. These properties make production, transport and refining difficult. In this study, we will focus on the problem of transport at the surface, mainly due to high viscosity. Transportation is currently possible using methods like dilution with a lighter oil or naphtha, oil-in-water emulsion, thermal treatment or upgrading methods (see the previous article in same review).

In order to improve them, we undertook rheological and structural studies to understand the links between the composition of the crude and its flow properties. We will focus on the two most polar and highest molecular mass components of the crude: asphaltenes and resins. It is well known since [1] that asphaltenes are responsible for the high viscosity of heavy oil. The originality of our study comes from the special attention paid to resins whose influence on rheology properties of crude oil is strongly linked to the role of asphaltenes. This description of the structure will help us to develop new methods of transportation of crude oils.

\section{EXPERIMENTAL PART}

\subsection{Rheological Experiments}

The rheological experiments were carried out on a controlled stress rheometer AR 2000. We used an aluminum cone and plate of $40 \mathrm{~mm}, 2^{\circ}$, gap of $49 \mu \mathrm{m}$ for the more viscous samples and double concentric cylinders with a gap of $100 \mu \mathrm{m}$ for the less viscous ones.

The relative viscosity $\eta_{r}$ of the solution has been calculated by dividing the absolute viscosity by the viscosity of the solvent. In the dilute regime of asphaltenes one can apply the Einstein Equation:

$$
\eta_{r}=1+[\eta] C
$$

where $C$ is the weight asphaltene concentration, $[\eta]$ is the intrinsic viscosity $(\mathrm{g} / \mathrm{g})$. The intrinsic viscosity is indicative of the shape of the particles (hydrodynamic perturbation) and is influenced by other contributions such as the interparticle pair interactions. The Huggins Equation allows us to separate hydrodynamic interaction from interparticle interactions [2]:

$$
\frac{\eta_{r}-1}{C}=[\eta]+k^{\prime}[\eta]^{2} C
$$

Here, $[\eta]$ is the true intrinsic viscosity, $k^{\prime}$ is the Huggins coefficient characterizing the ability of particles to aggregate in a considered solvent (pair interparticle interactions). These interactions result from the numerous forces acting on particles. In asphaltenes and resins aggregates, [3] shows that the main forces contain contributions from Van der Waals, Coulombic, repulsive exchange interactions (to prevent electronic orbitals from overlapping) and $\mathrm{H}$ bonding forces.

According to [4], these forces are so low compared with hydrodynamic interactions that Equation (1) is sufficient to describe the influence of asphaltenes on viscosity. We will show in the followings that we find a value of $k^{\prime}$ which cannot be neglected.

\subsection{Small Angle X-Ray Scattering (SAXS) Measurements}

This technique enables the observation of structural characteristics at small scales (5-500 $\mathrm{A}$ ), the experiments are sensitive to the difference of electronical density between the particles (asphaltenes) and the solvent. The measurements were performed on a spectrometer at the Institut français $d u$ pétrole. The $Q$ range was from $10^{-2}$ to $0.2 \AA^{-1}$. The sample cell used was a flat cell of $2 \mathrm{~mm}$ path length. All the scattering measurements were carried out at ambient temperature. In the dilute regime of asphaltenes, Zimm approximation is applied for small $q$ values:

$$
\frac{1}{I(q)}=\frac{1}{I(0)}\left(1+\frac{q^{2} R_{G}^{2}}{3}+\ldots\right) \text { for } q R_{G} \leq 1
$$

with $I(q)$ the scattering cross section (i.e. intensity in $\mathrm{cm}^{-1}$ ), $q$ the scattering vector, $R_{G}$ the radius of gyration $(\AA)$. In the dilute regime $(\phi \rightarrow 0), I(0)$ can be written as follows:

$$
I(0)=\Delta \rho^{2} \phi \frac{M}{d N_{A}}
$$

with $\Delta \rho^{2}$ the contrast, $\phi$ the volume fraction, $M$ the weightaveraged molecular weight, $d$ the specific gravity of dry asphaltenes and $N_{A}$ the Avogadro number. Practically, the plot of 1/I $(q)$ as a function of $q^{2}$ enables to calculate the radius of gyration and the molar mass of one aggregate of asphaltenes.

In the concentrated regime of asphaltenes, the radius and intensity are apparent values that enable to calculate the fractal dimension with:

$$
M \propto R_{G}^{D}
$$

with $D$ the fractal dimension. This number represents the compactness of the particles; a value of 3 is typical of dense 
particles. For reasonable polydispersity, three equations derive from (5):

$$
\begin{gathered}
R_{G} \propto \phi^{-\frac{1}{3-D}} \\
I(0) \propto \phi^{-\frac{3-2 D}{3-D}} \\
M \propto \phi^{-\frac{D}{3-D}}
\end{gathered}
$$

The behavior of asphaltenes solutions is often described by two models: the first one is to say that asphaltenes solutions behave like polymer solutions. Then asphaltenes are compared to solvated and macromolecular molecules $[5,6]$ while resins are considered as part of the solvent. The second model is to see asphaltenes solutions like insoluble and solid particles maintained in solution by resins. They are adsorbed on asphaltenes particles, providing a steric stabilization [7].

\section{INFLUENCE OF ASPHALTENES CONTENT ON RHEOLOGICAL BEHAVIOR}

Crude oils can be fractionated into four parts with different solubilities: Saturates, Aromatics, Resins and Asphaltenes (SARA). Resins and asphaltenes are the most polar and heaviest components of the crude. The saturates, aromatics and resins mix is called maltenes. Note that the influence of asphaltenes and resins on rheological properties has been studied on two heavy crude oils from different origins (Venezuela, Canada). Their SARA composition on the $\mathrm{C}_{20+}$ fraction are presented in Table 1.
Asphaltenes are easily extracted from the crude with a precipitating solvent: an alkane. The exact procedure is described elsewhere [8]. After drying, asphaltenes are shown as a dark powder.

TABLEAU 1

SARA fractionation on $\mathrm{C}_{20+}$ fraction (\%wt)

\begin{tabular}{c|c|c}
\hline & Venezuelan crude & Canadian crude \\
\hline Saturates & $15.9 \%$ & $16.0 \%$ \\
\hline Aromatics & $34.9 \%$ & $40.3 \%$ \\
\hline Resins & $36.3 \%$ & $32.2 \%$ \\
\hline $\begin{array}{c}\text { Asphaltenes } \\
\text { (extracted } \\
\text { with heptane) }\end{array}$ & $12.9 \%$ & $11.5 \%$ \\
\hline
\end{tabular}

In the followings, all data are results obtained on the heavy crude from Venezuela. The same trends have been observed on the other oil.

\subsection{Rheological Measurements}

Asphaltenes are extracted with pentane from Venezuelan crude. In this part, our aim is to study the influence of asphaltenes on rheological and structural properties. Rheological measurements are performed on solutions of these asphaltenes solubilized in xylene so that solvent does not contain initially any resin. All solutions have a Newtonian behavior in the shear rate domain (between 10 and $1000 \mathrm{~s}^{-1}$ ). The Figure 1 shows that above a critical

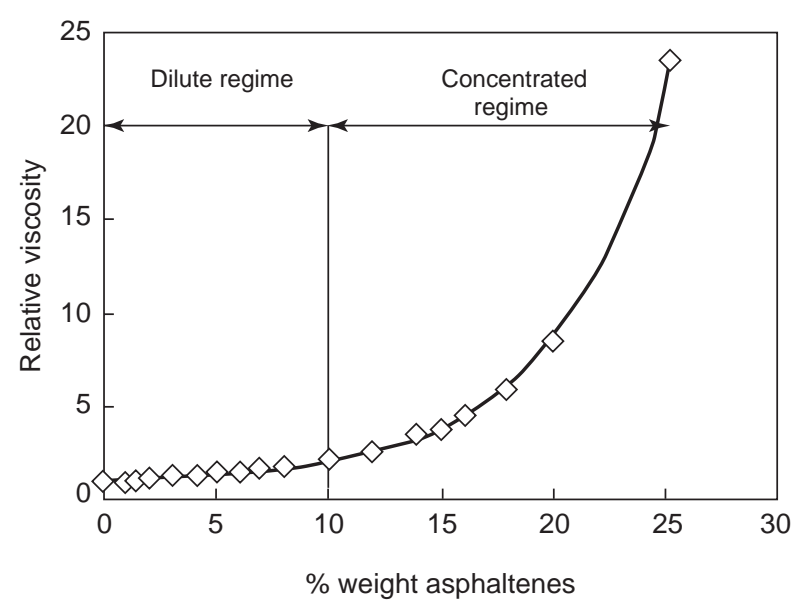

Figure 1

Influence of asphaltenes concentration on relative viscosity in xylene $\left(T=20^{\circ} \mathrm{C}\right)$.

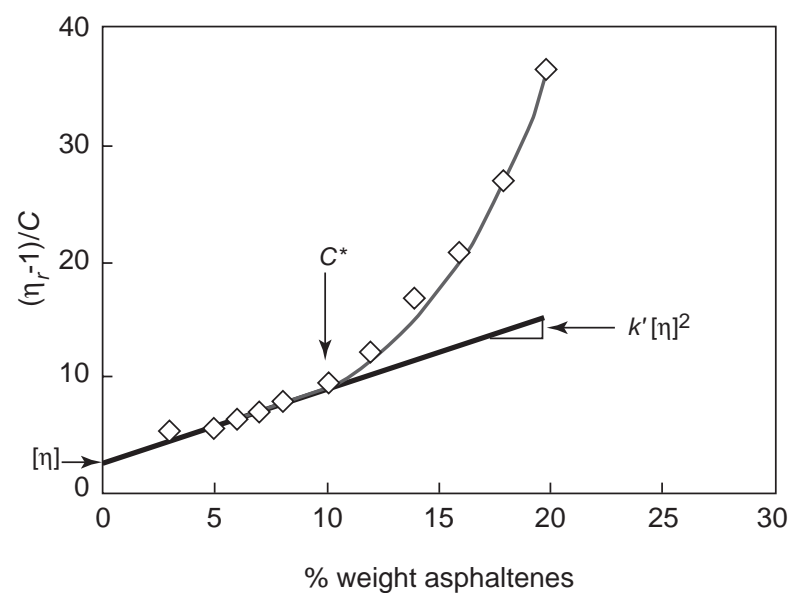

Figure 2

Determination of the overlap concentration $C^{*}\left(T=20^{\circ} \mathrm{C}\right)$. 
concentration $C^{*}$, the viscosity of the solution increases dramatically. Oscillatory experiments also show that above $\mathrm{C}^{*}$, elastic character becomes significant [8].

According to our convention, $C^{*}$ is precisely defined in Figure 2 as the maximum concentration where the Huggins Equation:

$$
\frac{\eta_{r}-1}{C}=[\eta]+k^{\prime}[\eta]^{2} C
$$

is valid to calculate intrinsic viscosity and Huggins coefficient. Their values are described in Section 3.1. Note that the errors bars are as the same order as the thickness of the dots.

\subsection{Small Angle X-Ray Scattering}

SAXS experiments have been performed to investigate the influence of the concentration of asphaltenes on structure. The scattering intensity normalized by the concentration is plotted in Figure 3 for five percentages of asphaltenes solubilized in xylene.

For scattering vectors above $0.1 \AA^{-1}$, all the curves superposed for all concentrations. It means that in the small scale, asphaltenes have an identical structure independently of the concentration. In a larger scale, curves are almost the same in the dilute regime but in the concentrated regime, the intensity decreases, showing that structure has changed. This has already been observed in [9].

SAXS experiments enable to calculate the radius of gyration which can be compared with rheological measurements. The Figure 4 confirms the existence of two domains of concentration. We note $C^{* *}$ the critical concentration measured by SAXS experiments. In the dilute regime, the radius of gyration is constant (in average $60 \AA$ ) so asphaltenes are independent particles, meaning that the viscosity increases linearly. In the concentrated regime, the interactions between asphaltenes are strong, so the asphaltenes overlap and the viscosity increases dramatically while the apparent radius of gyration diminishes.

We notice that $C^{* *}$ is lower than the $C^{*}$ overlap concentration measured by viscosity measurements. Ioan et al. [10] observed this difference in dextran solutions. They showed that $C^{*}$ can be ten times higher than $C^{* *}$. They explained that overlap concentrations are different because SAXS is a static measurement (microscopic changes) whereas viscosity experiments are dynamic measurements (macroscopic changes).

The average molecular weight of one aggregate is estimated by (4) at $123000 \mathrm{~g} / \mathrm{mol}$ and the mean radius is $60 \AA$ in the dilute regime. These values are close to ones found in [11] and [9]. The fractal dimension has been calculated with the four different Relations $(5,6,7,8)$ (Table 2). Without taking into account the Relation (7) because the value is quite far from the others (1.26), the fractal dimension is in average 1.51. It means that the asphaltenes are loose fractal objects.

TABLE 2

Fractal dimension of asphaltenes extracted with pentane in xylene

\begin{tabular}{c|c|c|c|c}
\hline Relation & $(5)$ & $(6)$ & $(7)$ & (8) \\
\hline$D$ & 1.47 & 1.54 & 1.26 & 1.52 \\
\hline
\end{tabular}

Rheological studies and SAXS measurements showed that asphaltenes have ability to overlap which causes the increase of viscosity and elastic character. In heavy oil, asphaltenes have the same properties but their role is influenced by the second component of the crude: the resins.

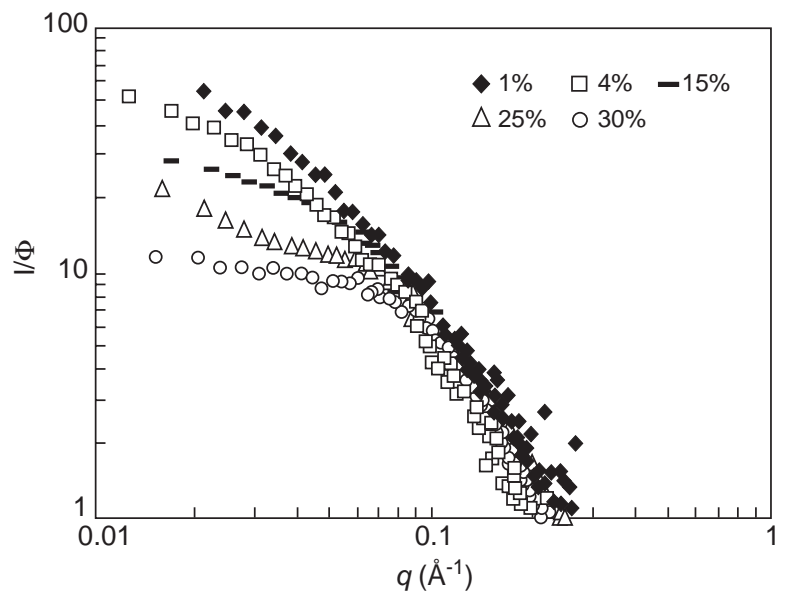

Figure 3

Scattering intensity normalized by asphaltene concentration in xylene $\left(T=20^{\circ} \mathrm{C}\right)$.

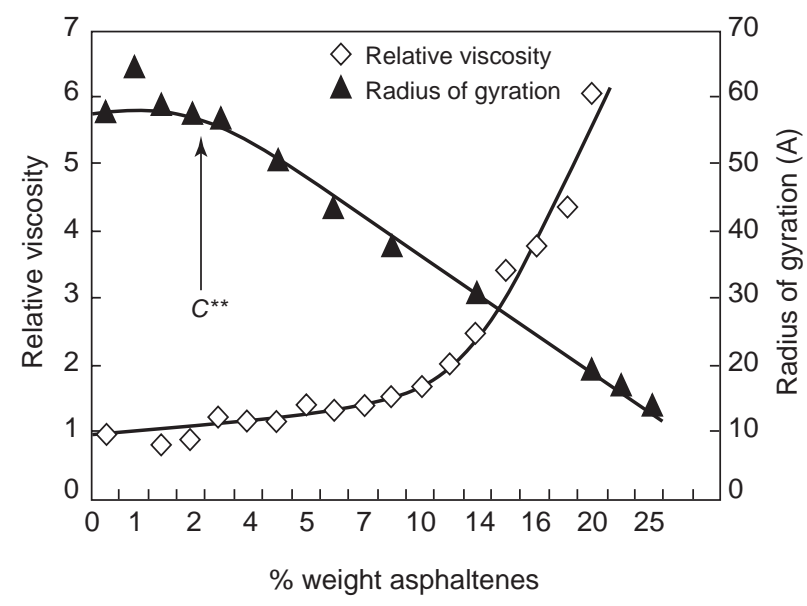

Figure 4

SAXS experiments and relative viscosities of asphaltenes in xylene $\left(T=20^{\circ} \mathrm{C}\right)$. 


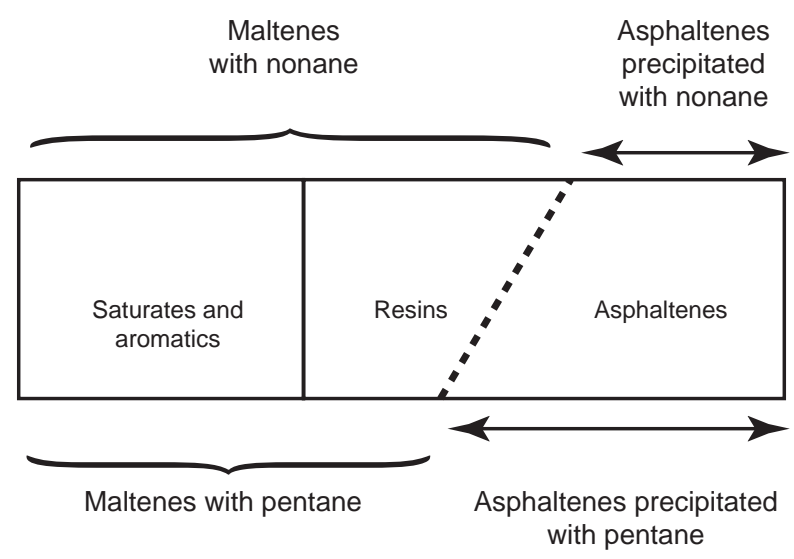

Figure 5

Asphaltenes extracted with two alkanes.

\section{INFLUENCE OF RESINS CONTENT ON RHEOLOGICAL BEHAVIOR}

In this part, our aim is to study the second component of crude oil: the resins. The quantity of resins in asphaltenes depends on the precipitating alkane. As shown in Figure 5, with a short alkane, the amount of asphaltenes is high (17\% weight of the crude) and they are rich in resins. With a longer alkane, the amount is lower (only 9.5\%) and the asphaltenes are poorer in resins than the former ones. In the followings, we note I5 the asphaltenes extracted with pentane and I9 the asphaltenes extracted with nonane. The symbol "I" means "insoluble".
One way to investigate the role of resins is to change the quantity of resins precipitated with asphaltenes. So we decided to study the rheological behavior and structural characteristics of asphaltenes rich in resins (I5) and poor in resins (I9). They are solubilized in different environments.

\subsection{Asphaltenes I5 and 19 in Xylene}

\subsubsection{Rheological Measurements}

Asphaltenes I5 and I9 are first solubilized in organic solvent which does not contain initially any resin. As previously, all solutions have a Newtonian behavior in the shear rate domain.

Relative viscosities of I5 compared with I9 are plotted on Figure 6. Two regimes of viscosity are observed for both I5 and I9. It shows that the resins, contained in higher quantity in I5, delay the apparition of the concentrated regime. It means that the critical concentration of I5 is higher than one obtained for the asphaltenes poor in resins. Moreover, in the concentrated regime, the resins also diminish the relative viscosity.

As previously, characteristics values are determined by using the Huggins Equation (2). The Figure 7 shows that intrinsic viscosities are the same for I5 and I9 while the slope of the linear curve is higher for I9 than for I5. Values are reported in Table 3. The overlap concentrations are exactly determined by our convention : it confirms that resins delay the increase of viscosity ( $C^{*}=5 \%$ for I9 against $10 \%$ for I5).

Table 3 resumes intrinsic viscosities $[\eta]$ and Huggins coefficients $k^{\prime}$ calculated for both kinds of samples in the dilute regime. In the row for I5, we present results calculated for I5 in xylene from previous SAXS results $\left(R_{G}=60 \AA\right.$,

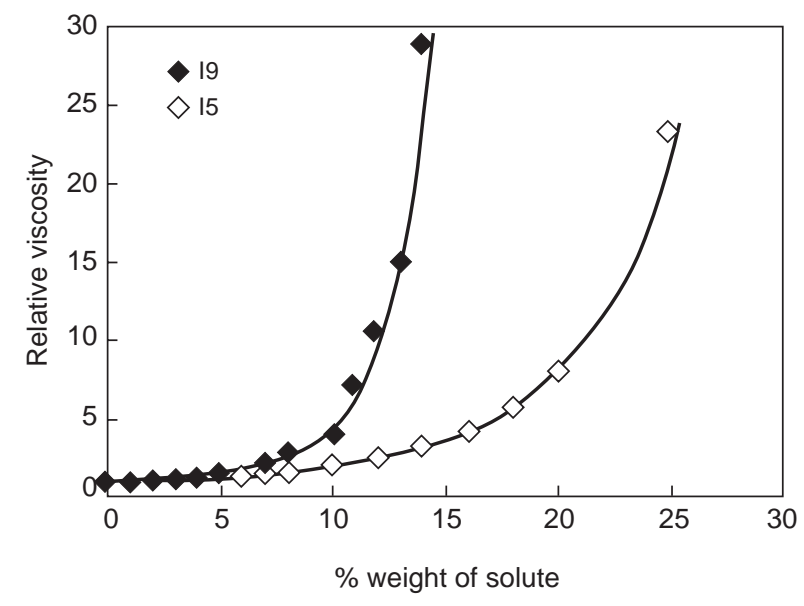

Figure 6

Relative viscosity of I5 and I9 in xylene $\left(T=20^{\circ} \mathrm{C}\right)$.

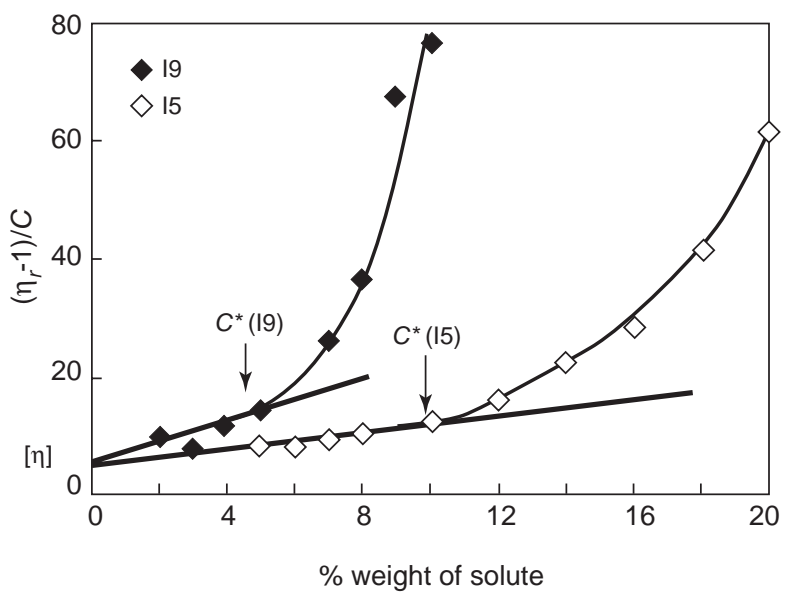

Figure 7

Determination of the overlap concentration $C^{*}$ for I5/xylene and $19 /$ xylene $\left(T=20^{\circ} \mathrm{C}\right)$. 
$M=123000 \mathrm{~g} / \mathrm{mol}$ ) and Equations (4) applied in polymers and Equation (8) applied in suspensions.

TABLE 3

Results of Huggins Equation in xylene at $T=20^{\circ} \mathrm{C}$

\begin{tabular}{c|c|c}
\hline Asphaltenes & I5 & I9 \\
\hline$[\eta] \mathrm{g} / \mathrm{g}$ & 3.6 & 3.6 \\
\hline$k^{\prime}$ & 3.6 & 6.4 \\
\hline
\end{tabular}

Another claim to confirm the inaccuracy of the analogy with polymer solutions is the relation between intrinsic viscosity and overlap concentration. Actually, we show that the relation:

$$
C^{*}=\frac{1}{[\eta]}
$$

applied in polymers [12] is not valid for our asphaltene solutions. The theoretical $C^{*}$ calculated for I5/xylene with an intrinsic viscosity of $3.6 \mathrm{~g} / \mathrm{g}$ is about $28 \% \mathrm{wt}$, which is much larger than the one measured with viscosity measurements $(10 \% \mathrm{wt})$. This difference can be explained because the asphaltenes are so associated that strong interactions between asphaltenes diminish the theoretical overlap concentration.

\subsubsection{Structural Interpretation}

Whatever the quantity in resins, intrinsic viscosity is almost the same for the two kinds of asphaltenes while the Huggins coefficients are different. Huggins coefficient $k^{\prime}$ is higher for I9, showing that asphaltenes I9 have more ability to associate than I5, then the viscosity increases more rapidly for I9.

This association is confirmed by tension surface [13] and calorimetry measurements [14] for asphaltenes in organic solvents. It is shown that the critical micelle concentration (CMC) is higher for I5 than the one of I9, showing less degree of association for I5.

It also means that asphaltenes I9 have larger size than those extracted with pentane. This has been confirmed by size exclusion chromatography in previous publication [14] and by SAXS experiments of asphaltenes in toluene [15]. Moreover, SAXS experiments on I9/xylene have been performed but they failed to measure the size of I9, showing again that its size is higher than one of I5.

Intrinsic viscosity is almost the same, probably because both $R_{G}{ }^{3}$ and the molecular mass $M$ increase with the same proportion so their ratio is almost equal in I5 and I9. Then we can propose the representation of I5 and I9 (Fig. 8) in three concentrations domains. In dilute regime $(C<5 \%)$, both $\mathrm{I} 5$ and $\mathrm{I} 9$ are independent particles with $\mathrm{I} 9$ having larger size than I5. Above 5\%, I9 are now overlapping whereas I5 are still independent asphaltenes. Above 10\%, both asphaltenes overlapped.
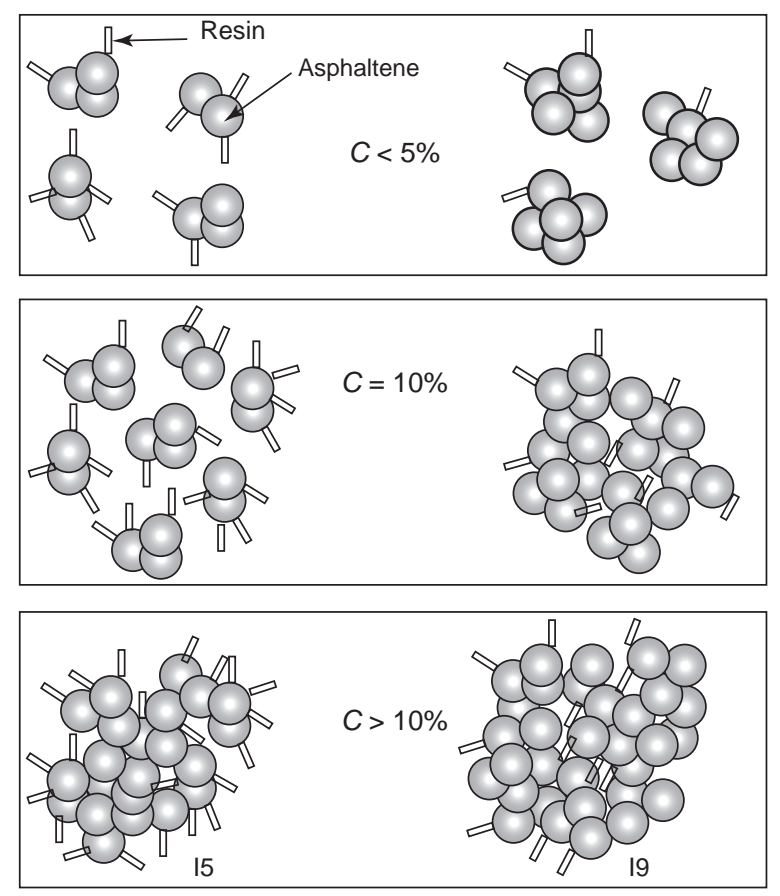

Figure 8

Representation of I5 and I9 in xylene in three domains of concentration.

We can deduce that the different overlap concentrations $C^{*}$ for I5 and I9 come from the different pair interparticle interactions $\left(k^{\prime}\right)$ and not from intrinsic viscosity values.

From these results we can assume that resins form a stabilizing layer around the asphaltenes, preventing them from associating. This is consistent with the notion of peptisation of asphaltenes by resins which has first been introduced by [16]. [17] showed that asphaltenes and resins are associated by hydrogen bonding interactions.

We showed that resins can both dissociate asphaltenes and stabilize them so they are able to reduce the viscosity of the solutions. In the following part, we study the role of resins in a solvent more representative of the reality where resins are in large quantity.

\subsection{Asphaltenes 15 and 19 in Maltenes}

\subsubsection{Rheological Measurements}

Several studies on the influence of asphaltenes on viscosity have been performed in organic solvents [18, 19], which are not really representative of the complexity of the crude. We proposed in previous publication [20] a recombining method where asphaltenes are solubilized in maltenes after a magnetic stirring at $80^{\circ} \mathrm{C}$ during $1 \mathrm{~h}$. We showed in [20] that heavy crude oil and its recombined sample have the same rheological and structural behavior. 
Figure 9 shows the relative viscosity of I5 and I9 solubilized in maltenes which are extracted with pentane. All solutions have a Newtonian behavior in the shear rate domain. We note that heavy crude is located in the concentrated regime where asphaltenes overlap (17\% wt in asphaltenes I5). As previously, resins reduce viscosity but the curves obtained for I5 and I9 are closer than in xylene, so overlap concentrations are almost the same (12\%) for I5 and I9.

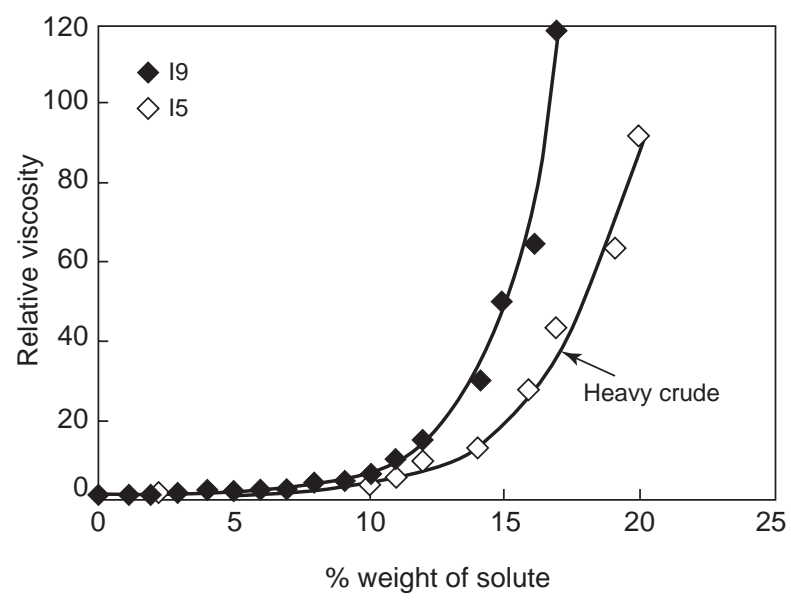

Figure 9

Relative viscosity of I5 and I9 in maltenes $\left(T=20^{\circ} \mathrm{C}\right)$.

The Huggins Equation applied in the dilute regime allows us to calculate intrinsic viscosities and Huggins coefficients presented in Table 4.

TABLE 4

Results of Huggins Equation in maltenes at $T=20^{\circ} \mathrm{C}$

\begin{tabular}{c|c|c}
\hline Asphaltenes & I5 & I9 \\
\hline$[\eta] \mathrm{g} / \mathrm{g}$ & 12.8 & 10.1 \\
\hline $\mathrm{k}$, & 1.7 & 2.3 \\
\hline
\end{tabular}

\subsubsection{Structural Interpretation}

Results show that intrinsic viscosities and Huggins coefficients are similar for I5 and I9. A possible explanation of this similarity is that in dilute regime, part of the resins of maltenes dissociate I9 and adsorb on their surface, making the two asphaltenes I5 and I9 very similar (Fig. 10). Sizes of the I5 and I9 are probably close in maltenes. When the concentration increases, I5 and I9 are so similar that we make almost no difference for the overlap concentration (Fig. 11).
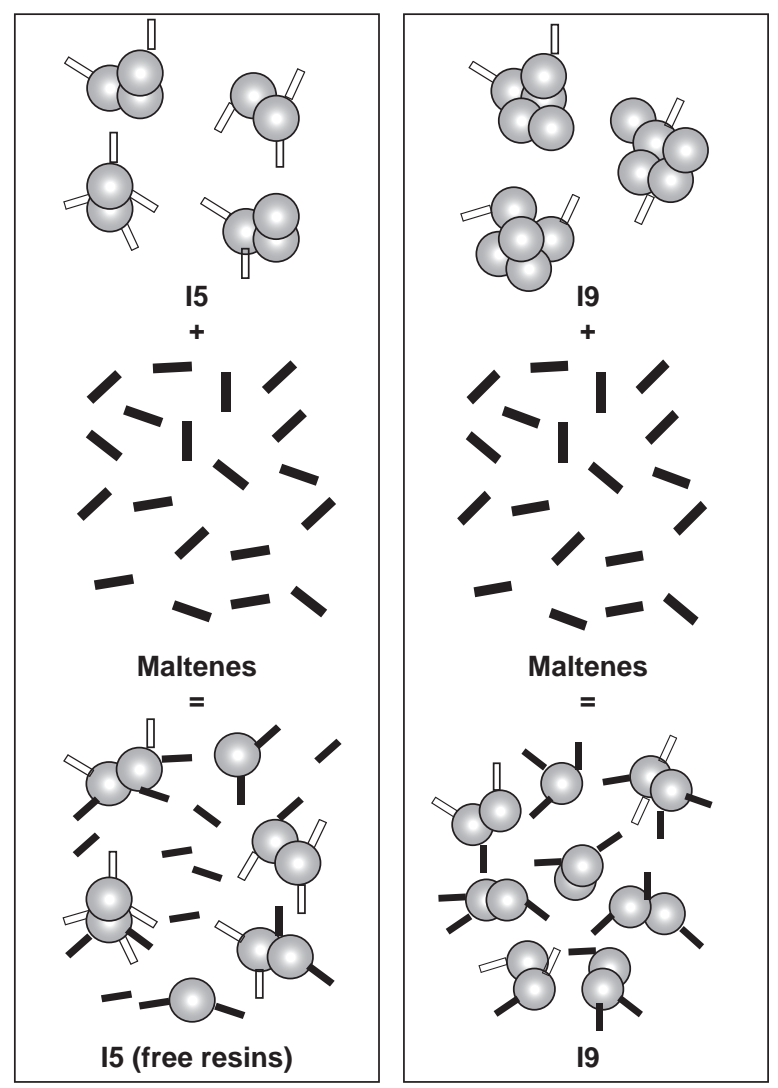

Figure 10

Schematic representation of I5 and I9 in maltenes in dilute regime.

We must note that intrinsic viscosities of I5 and I9 in maltenes are higher than ones obtained in xylene. On the contrary, Huggins coefficient of I5 and I9 are smaller in maltenes than ones obtained in xylene. It shows that asphaltenes are more associated than in xylene. This is confirmed by SAXS measurements already performed for I5 recombined samples for the same crude [8]. The contrast between asphaltenes and maltenes is so small that no molecular mass can be accurately measured so no intrinsic viscosity can be calculated. The mean radius of gyration is $40 \AA$ at $T=20^{\circ} \mathrm{C}$ (against $60 \AA$ in xylene). It means that in maltenes, resins dissociate and also stabilize asphaltenes in a larger extent than in xylene so that interactions are smaller than in organic solvent.

The Huggins coefficients are so small that overlap concentrations for I5 and I9 are more similar in maltenes than in xylene. The relation:

$$
C^{*}=\frac{1}{[\eta]}
$$

applied in polymers [12] is now valid for our asphaltene solutions in maltenes. We found a theoretical value of $8 \%$, 
which is not so far from the experimental one of $12 \%$. We can assume that solutions of asphaltenes in maltenes are close to polymer solutions because interactions between particles are smaller in maltenes than in xylene. Asphaltenes are probably more solvated than in xylene. Then molecular mass can be estimated using Equation (9) for polymer solutions. The mean calculated molecular mass is about $18000 \mathrm{~g} / \mathrm{mol}$ (against $123000 \mathrm{~g} / \mathrm{mol}$ measured by SAXS in xylene), which shows that asphaltenes are more dissociated in maltenes than in xylene.

Results showed the screening effect of maltenes which contain a large amount of resins. To confirm that resins can dissociate asphaltenes and reduce the interactions between asphaltenes, we decided to study the influence of polar components of asphaltènes: hexanol then nonylphenol.
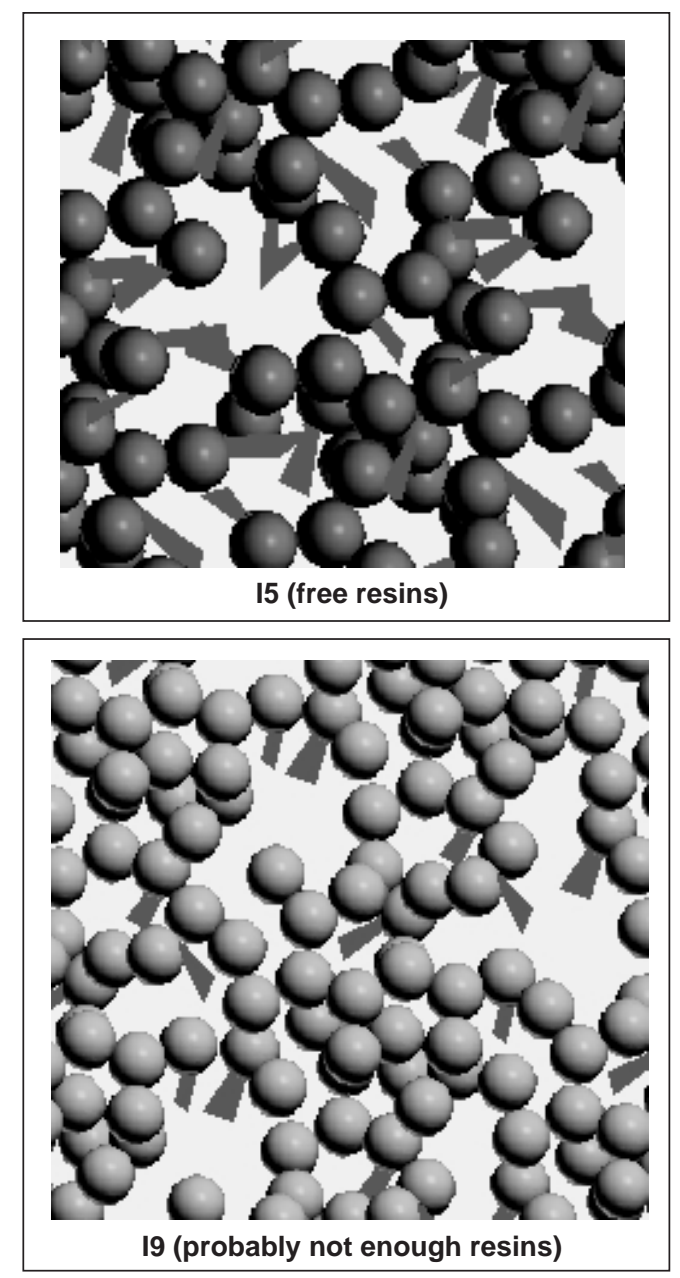

Figure 11

Schematic representation of I5 and I9 in maltenes in concentrated regime.

\subsection{Influence of Polar Components: Hexanol}

In order to describe the influence of polar solvents, we dissolve I7 asphaltenes in solvents containing increasing amounts of hexanol: toluene, toluene/hexanol (90/10 v/v), toluene/hexanol $(70 / 30 \mathrm{v} / \mathrm{v})$.

\subsubsection{Rheological Measurements}

Rheological measurements showed that addition of hexanol diminish the Huggins coefficient when the amount of hexanol is small (Table 5). Hexanol molecules act as peptizing agents of asphaltenes that are polar molecules too. As a combining effect, they also make the solvent more polar and reduce the attraction between polar parts of asphaltenes.

On the other side, intrinsic viscosity is noticeably increasing with the amount of hexanol (Table 5). As it is indicative of the shape of the particles (hydrodynamic perturbation), hexanol probably modify the structure of asphaltenes.

\section{TABLE 5}

$[\eta]$ and $k^{\prime}$ of I7 asphaltenes in toluene/hexanol $\left(T=20^{\circ} \mathrm{C}\right)$

\begin{tabular}{c|c|c}
\hline & {$[\eta] \mathrm{g} / \mathrm{g}$} & $k^{\prime}$ \\
\hline Toluene & 2.2 & 21.7 \\
\hline Toluene/hexanol 90/10 v/v & 3.2 & 6.2 \\
\hline Toluene/hexanol 70/30 v/v & 5.9 & 1.4 \\
\hline Toluene/hexanol 50/50 v/v & 4 & 5.9 \\
\hline
\end{tabular}

\subsubsection{SAXS Experiments}

SAXS measurements show that the radius of giration of asphaltenes slightly decreases when adding hexanol up to $10 \%$ in the solvent. It confirms that increasing the polar part of the solvent helps to reduce the aggregation of asphaltenes.

However a too high amount of hexanol induces another aggregation of the particle due to the higher polarity of the solvent. The increase of Huggins coefficient at a 50\% hexanol concentration (Table 5) is parallel to the increase of radius of gyration (Fig. 12).

\subsection{Nonylphenol as a Model of Resins}

Some amphiphiles are known to have a retarding effect on the precipitation of asphaltenes in alkane media [21-23]. We choose to study the effect of one amphiphile called nonylphenol. It was added to solutions I9 and I5 dissolved in xylene. Figure 13 shows the absolute viscosity of solutions of I9/xylene when adding nonylphenol. In the concentrated regime, viscosity decreases up to $10 \%$ of added nonylphenol then increases because of the high viscosity of pure 


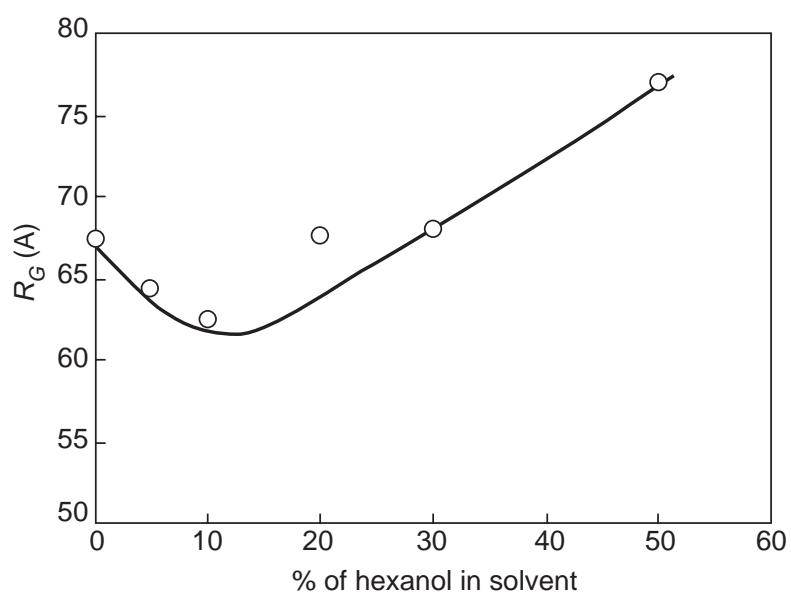

Figure 12

Decrease of radius of gyration of $3 \%$ wt asphaltenes I5 in toluene/hexanol blends $\left(T=20^{\circ} \mathrm{C}\right)$.

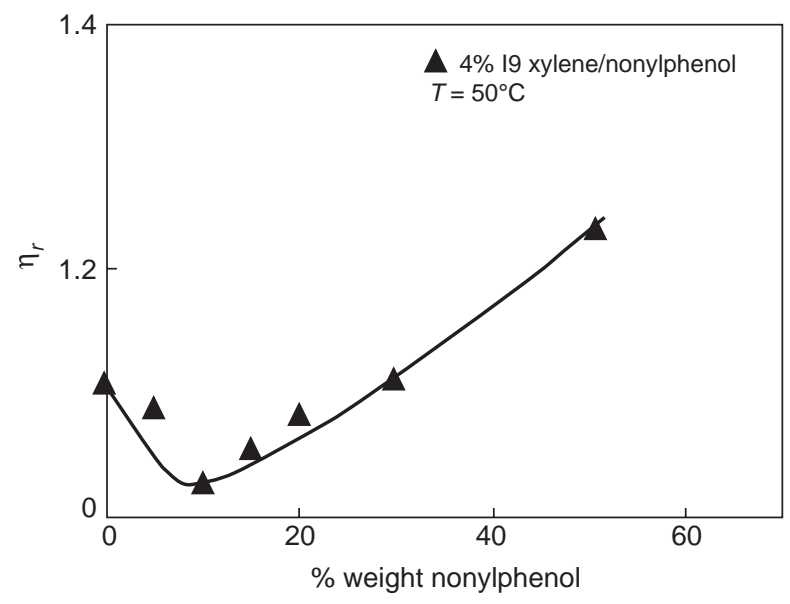

Figure 14

Decrease of relative viscosity in the dilute regime.

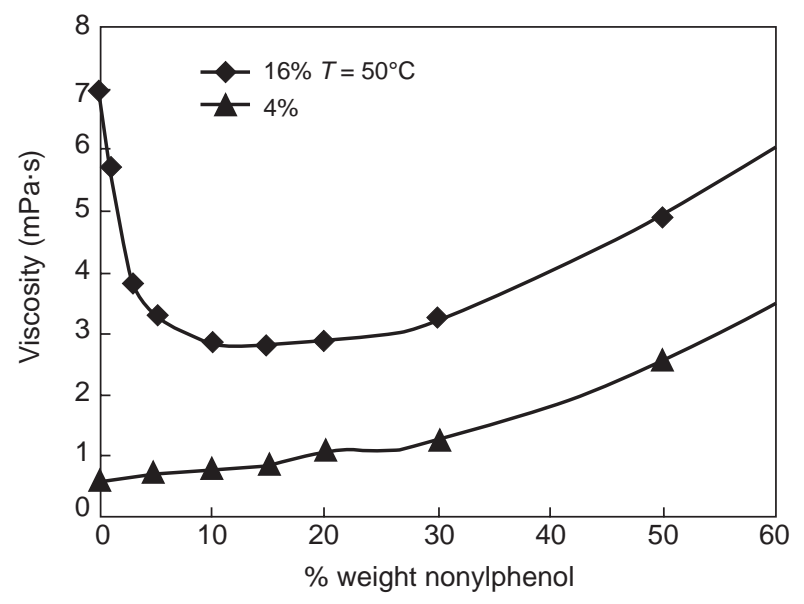

Figure 13

Absolute viscosity in dilute and concentrated regime as a function of $\%$ weight nonylphenol.

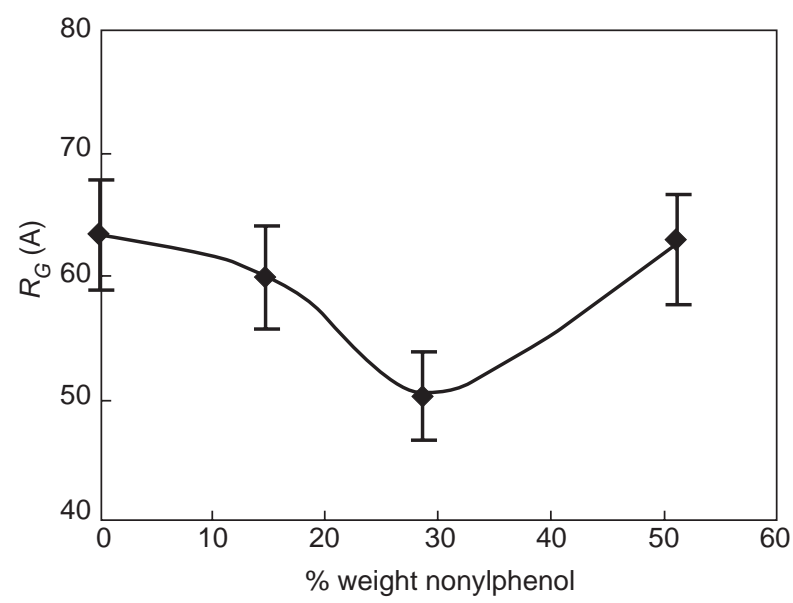

Figure 15

Decrease of radius of gyration of asphaltenes when adding nonylphenol in a $2.8 \%$ wt of I5 asphaltenes solution in toluene $\left(T=20^{\circ} \mathrm{C}\right)$. nonylphenol (18 $\mathrm{mPa} \cdot \mathrm{s})$. Same trend is observed in solution of I5/xylene but the decrease is lower than one observed for 19. This decrease has also been observed in experiments with natural resins added in a solution of $25 \%$ wt of asphaltenes I5 dissolved in saturates and aromatics mix [24].

In the dilute regime (4\% in asphaltenes), absolute viscosity (Fig. 13) increases regularly but relative viscosity (Fig. 14) shows a minimum at $10 \%$ of nonylphenol. These results show that nonylphenol have a structural effect on asphaltenes in both domains of concentration. Nonylphenol has two combining effects: it dissociates the asphaltenes and prevents them from associating by adsorbing onto the surface of asphaltenes so as to diminish the colloidal interactions.
So as to confirm the dissociation effect of nonylphenol, SAXS measurements were performed on solutions of $2.8 \%$ of I5 asphaltenes/toluene/nonylphenol. They proved the diminution of the radius of gyration (Fig. 15) and of the molecular mass when adding amphiphile, which can only be explained by the dissociation of asphaltenes particles. When adding nonylphenol in excess, asphaltenes have more tendency to associate, probably because the solvent is very polar.

\subsection{Influence of Temperature}

The study of temperature on viscosity is very important because it enables us to understand the combining effect of asphaltenes and resins. 


\subsubsection{From Ambient to High Temperatures}

In xylene, Figure 16 shows that Huggins coefficients are found to be thermal dependent. $k^{\prime}$ increases regularly with temperature, showing that high temperature facilitate the association of asphaltenes. SANS experiments in organic solvent $[25,26]$ showed that the radius of gyration and the molecular mass decreases as temperature increases. It means that asphaltenes dissociate, creating more numerous and smaller particles.

The dissociation of asphaltenes provoked by temperature releases numerous surfaces not covered by resins (in pink on Fig. 17). Then asphaltenes have more tendencies to associate (higher Huggins coefficient). I5 and I9 have probably close sizes at high temperature. We can also assume like [27] that

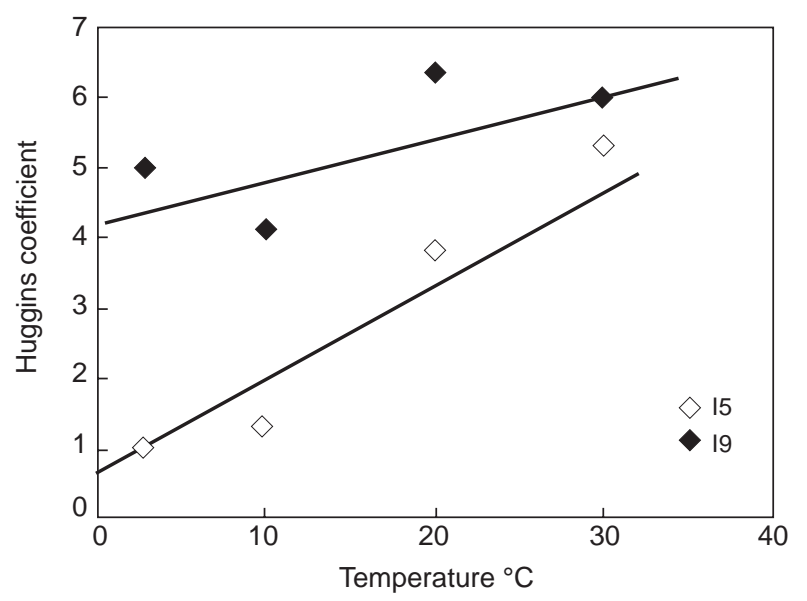

Figure 16

Huggins coefficient in xylene.

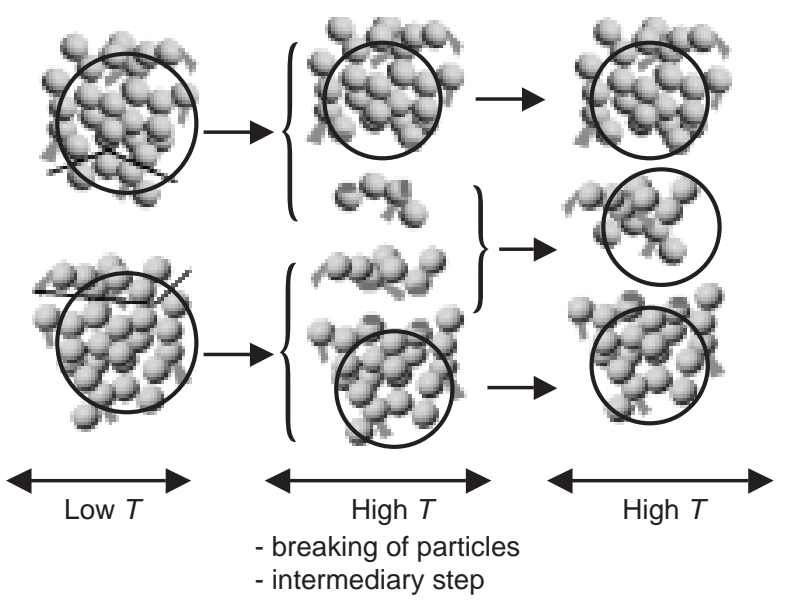

Figure 17

More particles but smaller ones for the same number of resins molecules in the whole solution (in xylene). asphaltenes are more numerous and so more closer. Therefore the short range interactions become stronger and the Huggins coefficient $k^{\prime}$ increases (Fig. 17).

In the presence of alcohol the interaction parameter $k^{\prime}$ does not vary with temperature (Table 6). When thermal dissociation occurs, alcohol molecules are linked to asphaltenes and make them less attractive: $k^{\prime}$ remains constant.

TABLE 6

[ๆ] and $k^{\prime}$ of I7 with varying amounts hexanol in solvent.

\begin{tabular}{c|c|c|c|c}
\hline \multirow{2}{*}{} & \multicolumn{2}{|c|}{ Toluene } & \multicolumn{2}{c}{$\begin{array}{c}\text { Toluene /hexanol } \\
(90 / 10) \mathrm{v} / \mathrm{v}\end{array}$} \\
\hline $\mathrm{T}^{\circ} \mathrm{C}$ & {$[\eta] \mathrm{g} / \mathrm{g}$} & $k$ & {$[\eta] \mathrm{g} / \mathrm{g}$} & $k^{\prime}$ \\
\hline 5 & 3.9 & 5.4 & 3.7 & 5.4 \\
\hline 10 & 3.3 & 9.3 & 3.9 & 4.5 \\
\hline 20 & 2.2 & 21.7 & 3.2 & 6.2 \\
\hline 30 & 2 & 21.5 & 3.5 & 4.5 \\
\hline
\end{tabular}

\begin{tabular}{c|c|c|}
\hline & \multicolumn{2}{|c|}{$\begin{array}{c}\text { Toluene /hexanol } \\
(50 / 50) \mathrm{v} / \mathrm{v}\end{array}$} \\
\hline $\mathrm{T}^{\circ} \mathrm{C}$ & {$[\eta] \mathrm{g} / \mathrm{g}$} & $k^{\prime}$ \\
\hline 5 & - & - \\
\hline 10 & 4.7 & 4.8 \\
\hline 20 & 4 & 5.9 \\
\hline 30 & 4 & 4.7 \\
\hline
\end{tabular}

Same trends are observed when adding nonlyphenol to aromatic solvent. It is confirmed that addition of polar component not only diminishes the dissociation of asphaltenes but also make them less dependant against temperature (Fig. 18).

In maltenes (Fig. 19), Huggins coefficient decreases with temperature and then remains constant above $40^{\circ} \mathrm{C}$. This non linearity could be related with the comparative evolution of Arrhenius plot.

In maltenes, temperature causes also the dissociation of asphaltenes. In this case, resins contained in maltenes adsorb onto the surface released after dissociation. This adsorption is all the more facilitated than temperature and smaller particles increase the Brownian diffusion of asphaltenes. Then Huggins coefficient decreases as temperature increases. It probably remains constant above $40^{\circ} \mathrm{C}$ because asphaltenes cannot be dissociated anymore.

\subsubsection{Shear Thinning Behavior at Low Temperatures}

We are going to study the oscillatory behavior of the crude oil at low temperatures. The geometry is a smooth aluminum plate-plate $(40 \mathrm{~mm}, 600 \mu \mathrm{m})$. A gap of $600 \mu \mathrm{m}$ has been 


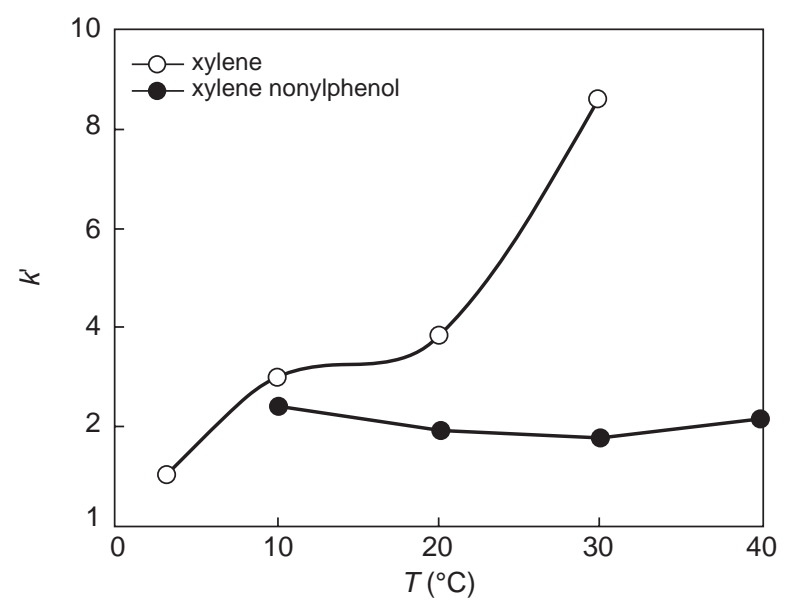

Figure 18

Huggins coefficient in xylene.

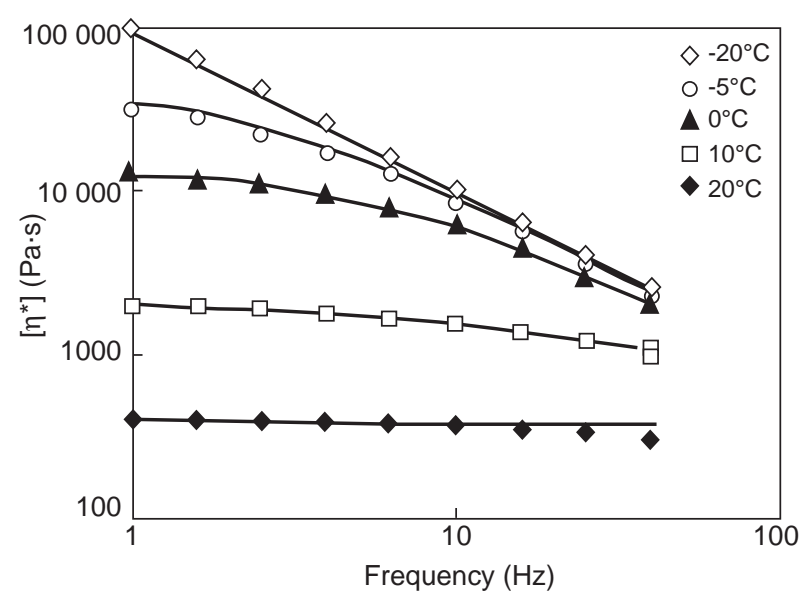

Figure 20

Shear thinning and Newtonian behavior of crude oil depending on temperature.

chosen to minimize the effect of wall slip. The oscillatory procedure has been applied between a frequency of 1 and 40 $\mathrm{Hz}$ with a $0.0125 \%$ strain which enables to stay in the viscoelasticity domain. The Figure 20 shows the influence of frequency on the complex viscosity $|\eta *|$. Above $10^{\circ} \mathrm{C}$, the rheological behavior is still Newtonian but below $10^{\circ} \mathrm{C}$, the crude oil behaves as a pseudo plastic fluid, showing a shear thinning without any yield stress.

The rheological measurements have been carried out at different temperatures, the master curve of the crude is then available (Fig. 21). At high frequencies it shows a constant modulus and a decrease of loss modulus. This lead us to assess that asphaltenes overlapping behave like a transient network of fractal aggregates.

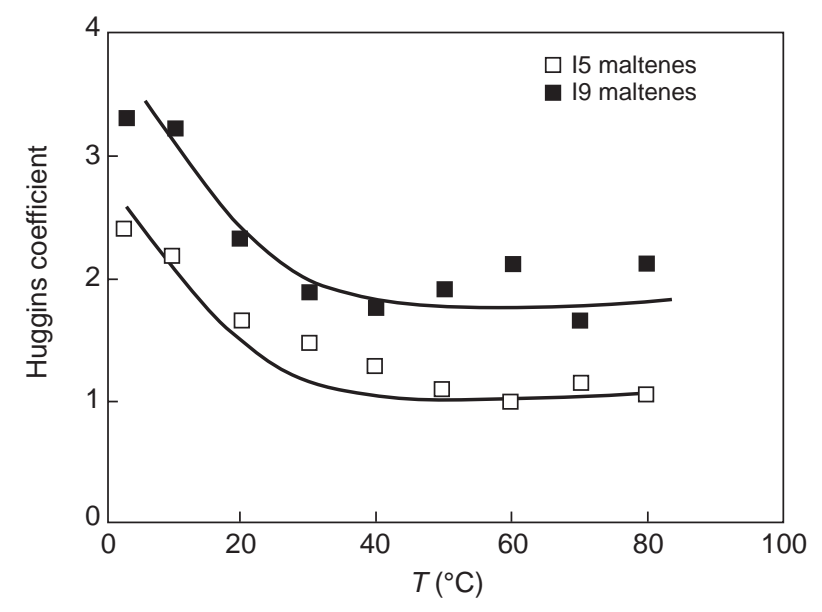

Figure 19

Huggins coefficient in maltenes.

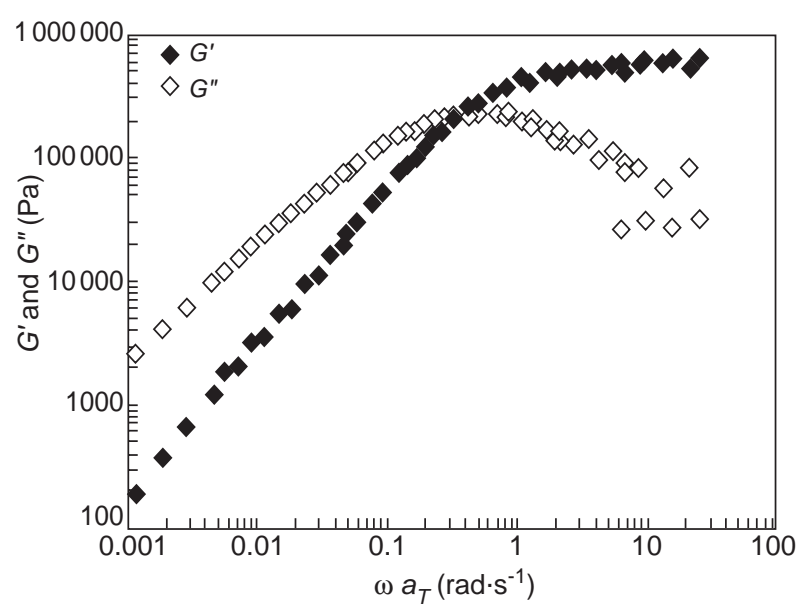

Figure 21

Master curve of crude oil.

In some crudes, wax components are likely to crystallize, which leads to shear-thinning behavior. We verify that no wax crystallization occurs in the crudes tested by differential scanning calorimetry measurements that show no crystallization peak. This shear thinning behavior is so attributed to the arrangement of overlapped asphaltenes under shear rate. In this concentrated regime, the particles interact with high colloidal forces : the asphaltenes overlap. At very low temperatures, the particles are totally immobilized. The shear rate deformation creates a breakage of these forces that have no time to reform. The viscosity is therefore lower than one measured at small shear rates and the crude behaves as a pseudo plastic fluid. At higher temperatures, asphaltenes have enough time to rearrange themselves and the product remains Newtonian. 
As it is shown in Figure 22, maltenes and a solution of asphaltenes in dilute regime (5\% I5 dissolved in maltenes) behave as Newtonian fluids. In both solutions, asphaltenes are independent particles. In crude oil (17\% in overlapped asphaltenes), the rheological behavior is shear thinning.

\section{CONCLUSION}

As a conclusion, high viscosity of heavy crude oil is due to asphaltenes overlapping. Viscosity is hard to measure in the well. NMR (Nuclear Magnetic Resonance) can be used to measure viscosity in situ and during production.

We show that asphaltenes behavior in xylene can hardly be compared to their behavior in real crude, that is to say in maltenes. Resins in maltenes have a strong dissociation effect, showing that asphaltenes association is a reversible phenomenon. We showed also that asphaltenes are very sensitive to polar components. This is a new way of improving dilution method: a small amount of alcohol can be added in naphta which is a common diluent of heavy crude.

Moreover, at low temperature, crude oil behaves like a shear thinning fluid. We showed that this behavior is due to a transient network of asphaltenes.

In another study, we showed that the crude oil viscosity can also be reduced by putting asphaltenes in maltenes at ambient temperature. As their dissolution rate is slow at this temperature, their overlapping is very decreased.

In a next study we will focus on the behavior of another type of crude: the foamy oils. Air droplets are trapped into these crudes. Due to depressurization during production, these droplets coalesce. We will study the influence of pressure on their behavior.

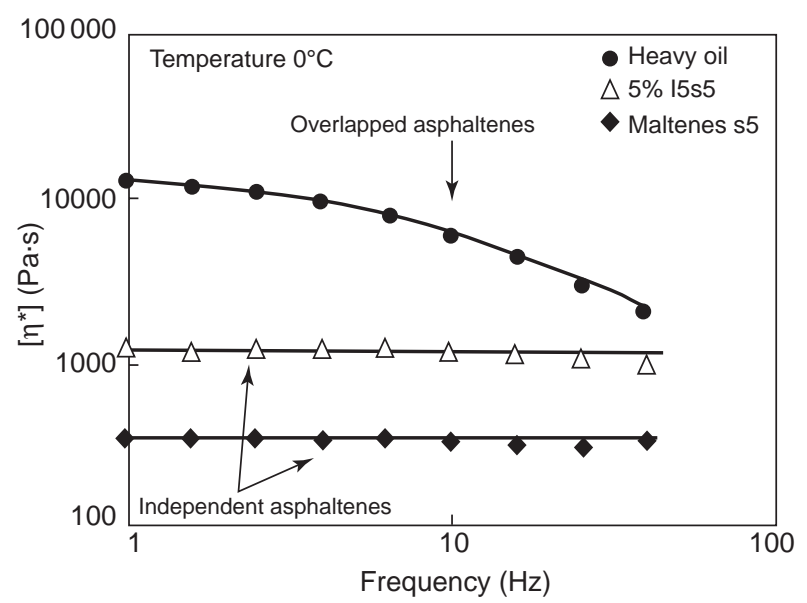

Figure 22

Influence of asphaltenes on shear thinning behavior $\left(\mathrm{T}=0^{\circ} \mathrm{C}\right)$.

\section{REFERENCES}

1 Mack, C. (1932) Colloid chemistry of asphalts. J. Phys. Chem., 36, 2901-2914.

2 Bouhadda, Y., Bendedouch, D., Sheu, E. and Krallafa, A. (2000) Some preliminary results on a physico-chemical characterization of a Hassi Messaoud petroleum asphaltene. Energy and Fuels, 14, 845-853.

3 Murgich, J. (2002) Intermolecular forces in aggregates of asphaltenes and resins. Petroleum Science and Technology, 20, 9-10, 983-997.

4 Storm, D.A. and Sheu E.Y. (1993) Rheological studies of Ratawi vacuum residue at 366 K. Fuel, 72, 233-237.

5 Hirschberg, A., De Jong, L.N.J., Schipper, B.A. and Meijers, J.G. (1984) Influence of temperature and pressure on asphaltene flocculation. Soc. Petrol. Eng. J., 6:283.

6 Laux, H., Rahimian, I. and Butz, T. (1997) Thermodynamics and mechanism of stabilization and precipitation of petroleum colloids. Fuel Processing Technology, 53, 69-79.

7 Altgelt, K.H. and Harle, O.L. (1975) The effects of asphaltenes on asphalt viscosity. Ind. Eng. Chem. Prod. Res. Dev., 14, 240.

8 Hénaut, I., Barré, L., Argillier, J.F., Brucy. F. and Bouchard, R.(2001) Rheological and structural properties of heavy crude oils in relation with their asphaltenes content. SPE 65 020, Oil Field Chemistry, Houston, USA, 13-16 Feb.

9 Espinat, D., Rosenberg, E., Scarsella, M., Barre, L., Fenistein, D. and Broseta, D. (1998) Colloidal structural evolution from stable to flocculated state of asphaltene solutions and heavy crudes. In: Structures and Dynamics of Asphaltenes, edited by Mullins and Sheu, Plenum Press, New York.

10 Ioan, C.E., Aberle, T. and Burchard, W. (2001) Light scattering and viscosity behavior of dextran in semi-dilute solution. Macromolecules, 34, 2, 326-336.

11 Champetier, G., Monnerie, L. (1969) In: Introduction à la chimie macromoléculaire, Éditions Masson \& Cie, 15 and 329.

12 De Gennes, P.G. (1979) Scaling Concepts in Polymer Physics, Cornell University Press.

13 Mohamed, R.S. and Ramos, A.C.S. (1999) Aggregation behavior of two asphaltenic fractions in aromatic solvents. Energy and Fuels, 13, 323-327.

14 Andersen, S.I., Del Rio, J.M., Khvostitchenko, D., Shakir, S. and Lira-Galeana, C. (2001) Interaction and solubilization of water by petroleum asphaltenes in organic solution. Langmuir, 17, 307-313.

15 Fenistein, D. (1998), Structure colloïdale des produits pétroliers lourds. PhD Thesis, University of Paris 6.

16 Pfeiffer, I. and Saal, R.N.J (1940) Asphaltic bitumen as colloid system. J. Phys. Chem., 44, 139.

17 Moschopedis, S.E. and Speight, J.G. (1976) Investigation of hydrogen bonding by oxygen functions in Athabasca bitumen. Fuel, 55, 187-192.

18 Sheu, E.Y., De Tar, M.M. and Storm, D.A. (1991) Rheological properties of vacuum residue fractions in organic solvents. Fuel, 70, 1151-1156.

19 Sheu, E.Y., Storm, D.A. and De Tar, M.M. (1991) Asphaltenes in polar solvents. J. of Non Crystalline Solids, 131-133, 341-347.

20 Argillier, J.F., Coustet, C. and Hénaut, I. (2002) Heavy oil rheology as a function of asphaltenes and resin content and temperature. SPE 79 496, International Thermal Operations and Heavy Oil Symposium and International Horizontal Well Technology Conference, Calgary, Canada, 4-7 Nov. 
21 Gonzalez, G. and Middea, A. (1991) Peptization of asphaltenes by various oil soluble amphiphiles. Colloids and Surfaces, 52, 207-217.

22 Chang, C.L. and Fogler, H.S. (1994). Stabilization of asphaltenes in aliphatic solvents using alkylbenzene derived amphiphiles. 1. Effect of the chemical structure of amphiphiles on asphaltenes stabilization. Langmuir, 10, 1749-1757.

23 Lian, H., Lin, J.-R. and Yen, T.F. (1994). Peptization studies of asphaltene and solubility parameter spectra. Fuel, 73, 3, 423-428.

24 Argillier, J.-F., Barré, L., Brucy, F., Dournaux, J.-L., Hénaut, I. and Bouchard, R. (2001) Influence of asphaltenes content and dilution on heavy oil rheology. SPE 69 711, International Thermal Operations and Heavy Oil Symposiums, Porlamar, Margarita Island, Venezuela, 12-14 March..
25 Roux, J.N., Broseta, D., Demé, B. (2001) SANS study of asphaltenes aggegation: concentration and solvent quality effects. Langmuir, 17, 5085-5092.

26 Thiyagarajan, P., Hunt, J.E., Winans, R.E., Anderson, K.B. and Miller, J.T. (1995) Temperature dependent structural changes of asphaltenes in 1-methylnaphthalene. Energy \& Fuels, 9, 839-833.

27 Tanaka, R, Hunt J.E., Winans, R.E., Thiyagarajan, P., Sato S. and Takanohashi T. (2003) Aggregates structure analysis of petroleum asphaltenes with small angle neutron scattering. Energy and Fuels, 17, 127-134.

Final manuscript received in September 2004 